University of Nebraska - Lincoln

DigitalCommons@University of Nebraska - Lincoln

To Improve the Academy

Professional and Organizational Development Network in Higher Education

1994

Faculty Perceptions of Undergraduate Teaching

Deborah Olsen

Ada B. Simmons

Follow this and additional works at: https://digitalcommons.unl.edu/podimproveacad

Part of the Higher Education Administration Commons

Olsen, Deborah and Simmons, Ada B., "Faculty Perceptions of Undergraduate Teaching" (1994). To Improve the Academy. 317.

https://digitalcommons.unl.edu/podimproveacad/317

This Article is brought to you for free and open access by the Professional and Organizational Development Network in Higher Education at DigitalCommons@University of Nebraska - Lincoln. It has been accepted for inclusion in To Improve the Academy by an authorized administrator of DigitalCommons@University of Nebraska - Lincoln. 


\section{Faculty Perceptions of Undergraduate Teaching}

\section{Deborah Olsen}

\section{Ada B. Simmons}

Indiana University

The purpose of this study was to construct an accurate depiction of the undergraduate teaching portion of the faculty role at a large, public research university, drawing from interviews conducted with 114 faculty. The interview schedule investigated teaching load, course goals, perceptions of undergraduate students, modes of evaluating student learning, office hours and advising, professional role interests and time allocation, feedback about teaching performance, strategies for improving teaching, and satisfaction with teaching. The findings of the current study reveal that faculty are highly committed to undergraduate teaching and are profoundly concerned with students' intellectual development. Results also suggest how complex college teaching has become in terms of the range of preparation, abilities, and motivation students bring to the classroom; the difficulties inherent in creating an active, engaging learning environment in large lecture courses, and the competition faculty face from other professional demands upon them. Despite an interest in their undergraduate teaching role, faculty remain perplexed by students' lack of interest in a subject matter faculty find compelling, by new technologies and techniques that take time and resources to master, and by escalating external demands to teach more and teach better, without a clear understanding of what this means or how it is to be accomplished. Nevertheless, in the face of significant challenges, the majority of 
faculty find satisfaction in teaching and interacting with undergraduate students.

The trademarks of prestigious research universities are well-known: their programs of research are on the cutting edge of discovery and progress, spearheaded by esteemed researchers and scholars who sucessfully garner financial support to sustain their enterprises. But what of the role of undergraduate teaching within such institutions, particularly large public universities? What sorts of teaching activities, practices, and attitudes prevail and characterize scholars in the classroom? How do such faculty feel about the undergraduate students they teach and their teaching itself? How do they assess student learning and the effectiveness of their own teaching? Has the success in the research domain come at the expense of interest, satisfaction, and effectiveness in teaching undergraduate students?

Debate over the conflict between research and teaching is certainly not new. However, the downswing of the nation's economy (and the consequent emphasis on fiscal accountability), the rise of the student consumer movement, and the proliferation of books and articles in the popular press bashing higher education have brought a new urgency and perhaps even a new way of thinking to the debate. Re-examination of faculty roles requires, however, reliable and specific information on the nature of faculty's current endeavors, particularly in the area of teaching where documentation and evaluation have traditionally been more limited.

The purpose of this study was to construct an accurate depiction of the undergraduate teaching portion of the faculty role at a large public research university, drawing from faculty's own perceptions of their teaching activities; the manner in which they carry out these responsibilities; and the meaning, sense, and satisfaction they derive from their teaching experiences. In doing so, we hoped not only to establish a body of baseline empirical data on the teaching activities of the faculty at this institution but also to compare the pedagogical behaviors and attitudes of these faculty to those the literature suggests are conducive to the intellectual development of undergraduate students. Finally, we hoped that the effort would help us begin to identify factors that contribute to sustained faculty interest and vitality in 
undergraduate teaching throughout the course of a career, and conversely, those which may lead to disinterest, demoralization, and teaching ineffectiveness.

In the Spring of 1992, 114 faculty from the School of Business (13\%) and the College of Arts and Sciences (87\%) were interviewed about their undergraduate students and their undergraduate teaching. An interview schedule (available from authors), developed from previous faculty interviews and the literature on college teaching, investigated teaching load, course goals, perceptions of undergraduate students, modes of evaluating student learning, office hours and advising, professional role interests and time allocation, feedback about teaching performance, and strategies for improving teaching. Interview data were supplemented with a questionnaire designed to assess faculty's use of specific instructional practices (Chickering, Gamson, \& Barsi, 1987). The vast majority of faculty (83\%) contacted agreed to participate; all had taught at least one undergraduate course in the past two years. Of the faculty in the College of Arts and Sciences, $41 \%$ were in the Arts and Humanities, $29 \%$ in the Social Sciences, and $31 \%$ in the Hard Sciences. Eighty-three percent of respondents were male and $92 \%$ were white; males and whites were somewhat overrepresented in our sample due to uneven sample attrition. Four-andone-half percent of the sample were Asian, and less than $4 \%$ were African-American, Hispanic, Native-American, or "other." Of those interviewed, $30 \%$ were assistant professors, $30 \%$ were associate professors, and $40 \%$ were (full) professors. Faculty had spent a mean of 12 years at the university.

\section{Teaching Load}

Faculty participating in the study indicated an average load of about 3.7 courses compared to a campus-wide load of about 3.9 per year, roughly comprised of three undergraduate and one graduate course per year. The average class size was 62 students. About two-thirds of faculty reported teaching at least one course at the freshman or sophomore level.

Faculty were also asked about how they allocate their time. Empirical data have consistently confirmed that faculty at Research 1 
universities work a 55 to 60 hour week (Mingle, 1993). Overall, faculty in our sample devoted the largest percentage of their (44\%) time to teaching and the smallest $(21 \%)$ to service. Research activities comprised $35 \%$ of their time. (Campus figures were comparable to national data for public research universities) (National Center for Education Statistics, 1991). Out-of-class teaching tasks (preparation, grading, office hours) required more than twice as much time as spent in-class.

Faculty responses indicated high levels of input about choice and scheduling of courses. Interestingly, almost $75 \%$ rated their teaching load as reasonable or very reasonable in terms of the professional demands upon them, but only $53 \%$ gave the same ratings when considering students' needs.

\section{Teaching Goals}

Successful strategists, from winning basketball coaches to military heroes, have defined goals or objectives and thoughtfully orchestrated plans for achieving them. College teachers are no exception. McKeachie (1993) suggests that the first step in preparing for a course is the development of course objectives because the course objectives will, in turn, drive the choice of text, the type and order of assignments, and the choice of teaching techniques. The vast majority of faculty in this study explicitly articulated the goals of their undergraduate courses in lecture and on their syllabus. Faculty reported being predominantly concerned with students' mastery of subject matter and critical thinking or the ability to effectively analyze, synthesize, and communicate that subject matter. One faculty member stated, "My goal is to bring students to intellectual maturity, to bring their reasoning performance up a level, to help them learn how to study and think inferentially, and to draw conclusions deductively." And in the words of another: "My goal is to give students preparation for life-the development of openness, flexibility, and critical thinking." An emphasis on teaching students "to think"- to comprehend the conceptual relationships among the facts and principles of a discipline-rather than on memorization of isolated concepts, definitions, and facts, is critical in formulating problem-solving skills that students will find 
useful in their careers and throughout the rest of their lives (McKeachie, Pintrich, Lin, \& Smith, 1986). Some faculty also endorsed as fundamental to the undergraduate intellectual journey the acquisition of better perspective-taking skills and a deep-seated intellectual curiosity about the world. As one faculty stated, "Mastering material is not the main goal; in six months they won't remember much. I'm more interested in getting them interested in learning for its own sake, to get them to be more motivated and more confident about their own ability." In this way, the acquisition of disciplinary knowledge becomes the means to an end by encouraging intellectual curiosity and interest. And from another: "I want students to be able to realize that there are multiple perspectives, that there's a difference between facts and opinions...that in coming to the academy they can resituate opinions and beliefs in terms of other perspectives, not either/or...they can analyze perspectives and come to an informed opinion of their own and get beyond the notion of one right answer." Others wanted to prepare students for a career. Fewer sought course outcomes directly influencing the socio-emotional development of students.

Over half of all faculty mentioned student characteristics as a key factor in setting course goals. Although course level (introductory or advanced) and curricular requirements were also widely reported (42\% and $37 \%$, respectively), it is important that it was the background, aptitudes, and interests of students that faculty found particularly pressing, more so than purely academic notions of curricular rigor or disciplinary infrastructure.

About $75 \%$ of faculty felt that, in general, they achieved their course goals. In determining this, they relied most often on student performance on tests and exams. About half of the faculty also spoke with students from the class, gleaning ideas and impressions from these conversations. Formal student evaluations had considerably less influence. Faculty may be inclined to rely more on student comments when they know the student providing the information and, more importantly, when they are able to probe students' responses and determine more specifically which aspects of a course were successful, which were not, and why. 


\section{Student Learning: Expectations and Evaluation}

Most faculty expected students to study between five and eight hours weekly (mean=seven hours) per course. These figures were substantially higher than students' own reports of the time they spent studying. (A campus study revealed that $30 \%$ of the freshmen studied 10 hours or less per week.) Nevertheless, relatively few faculty (26\%) explicitly told students how much time they should be spending on their studies. Although many faculty were aware of the current emphasis on setting explicit "time on task" guidelines for students, they argued that the training and aptitudes of students in a public university vary substantially enough that such guidelines are as apt to be misleading as helpful. In a more philosophical vein, many faculty also felt that determination of study time was an issue most appropriately left, at the college-level, to students themselves.

Despite substantial recent innovation in the number and variety of methods of evaluating student learning (Angelo \& Cross, 1993), faculty continue to rely on traditional formats. On average faculty used about two types of performance measures per course with far more using some form of in-class test (quizzes, exams, etc.) than any other type of evaluation. Papers, participation in class discussion, and homework were next most frequently used. This overall profile of evaluation techniques remained relatively constant although more faculty teaching at the upper level included papers and class participation in determining students' grades. In-class tests were not only the most common measure of student performance but, when employed in a course, accounted for a substantial proportion of students' grades (68\%-73\%). Papers, when assigned, accounted for about $40 \%$ of students' grades, and homework and class participation contributed approximately $18 \%$. There is evidence that in-class exams tend to tap different competencies and even elicit different study methods than papers and presentations (Wolf, Schmitz, \& Ellis, 1991).

\section{Tests}

When asked more specific questions about the tests and exams they typically give (those they use in at least half of the classes they teach), a majority of faculty indicated they test three times or less a 
semester. Consistent with these schedules, only $18 \%$ of faculty gave any type of test in the first two weeks of class and $35 \%$ gave their first exam in about the fifth week (one-third into the semester). There was a tendency for faculty teaching lower level courses to test earlier in the semester. Data thus suggested that faculty were cognizant of freshmen and sophomores' greater need for feedback to calibrate their own mastery of course materials but did not, in general, provide feedback in intervals shorter than four to five weeks.

Sixty-five percent of faculty included some type of short answer or essay question on tests (of this $65 \%, 12 \%$ were short answer, $22 \%$ essay, $66 \%$ both), though the practice was more common in upper level courses. Virtually all (88\%) faculty tried to provide written comments on essay answers. In fact, faculty indicated that, most often, they assumed primary responsibility for grading students' tests although again, course level (and course size) made a difference. These teaching entry level courses, in particular, relied more heavily on machine grading and teaching assistants while in upper level courses faculty tended to grade tests themselves.

Almost all faculty said they have asked students to come to their office to discuss an exam, but only a third do this "frequently" or "very frequently." In general, (90\%) faculty called students to their office to discuss poor performance. In addition, faculty spoke to students whose test scores were inconsistent with their other work in the course (27\%), students who had misinterpreted an assignment (14\%), who had cheated $(16 \%)$, or who had performed exceptionally well $(11 \%)$. Given recent research on pedagogy and assessment (Angelo \& Cross, 1993), faculty need better information about how timely and varied learning measures can serve as both effective feedback and documentation of student mastery, moving their teaching agenda forward in useful directions.

\section{Papers}

Approximately two-thirds of faculty required a paper or writing assignment in at least one of their courses. Papers were, however, almost twice as likely to be assigned in upper rather than lower level classes. A majority of faculty (66\%) reported giving students a "fair 
amount" or "great deal" of latitude in choosing a paper topic. To help students formulate their ideas, $88 \%$ of faculty invited or required students to discuss their paper before submitting it although few students used this opportunity. There was more interaction with students after a paper had been graded, with $46 \%$ of faculty rating such discussions as occurring "sometimes" and $29 \%$ "frequently" or "very frequently". As with testing, students' failure to perform at a satisfactory level was the primary reason to meet about a paper. Faculty also discussed good papers with students to encourage them to develop their ideas or to consider the discipline as a major. Plagiarism was another, though less frequent, concern. According to faculty, student papers routinely recounted facts or offered unsupported opinion. Grading was described as time-consuming because students often lacked basic summary and grammar skills. The following comment was fairly typical: "I still write extensive comments. I write at most four or five sentences of summary comments plus extensive comments in the text on grammar, vocabulary, or factual problems. My wife thinks I'm crazy in the amount of time I spend grading papers; I think I'm crazy too." 1

\section{Students with Needs for Additional Academic Support}

In the context of assessing student learning we wondered, if and how faculty identify students who need more help than is provided through the normal course, and what faculty do to support these students. Through tests and papers over $80 \%$ of faculty became aware that certain students were having particular difficulty with a class. However, exams and writing assignments often occurred after a substantial portion of the semester had elapsed. Thirty-one percent of faculty reported that conversations with students outside class revealed student learning problems. More indirect indicators such as absence from class and behavior in class were cited by even fewer

\footnotetext{
'Freshman writing tests administered on the same campus demonstrated significant deficiencies in students' ability to summarize and analyze relatively simple text materials. Sentence-level skilld (grammar and construction) appeared stronger.
} 
faculty ( $8 \%$ and $18 \%$ respectively). Class size undoubtedly affects faculty's ability to monitor such indicators. Approximately threefourths of faculty said that they do initiate contact with students identified as having significant academic problems. When asked how many students they have done this with in the past two years, 52\% gave a range of one to three students, $34 \%$ a range of four to ten students.

A majority of faculty arranged an out-of-class conversation with students to discuss their problems but by and large tended to recommend them to the student academic center (47\%) (a campus service offering workshops to help traditional and non-traditional students acquire college-level study skills), rather than attempt to work with them directly $(27 \%)$ or have an associate instructor (graduate teaching assistant) work with them (14\%). Interestingly, about $18 \%$ of faculty also advised students to drop the course. Faculty's reticence to become more directly involved helping such students stems from their concern that some students' basic abilities - their academic preparation and their motivation - are just not adequate for college level work, and the remediation required is beyond the resources and expertise of individual faculty and perhaps even the university.

\section{Perceptions of Undergraduate Students}

Changing demographics and characteristics of students can also pose challenges to even the most skilled instructors. To be effective teachers, faculty must be able to build links between the knowledge they wish to impart to students and that which students already possess. Acquiring this depth of knowledge about students requires an ongoing assessment of their strengths and weaknesses, levels of preparation, intelligence, motivation, and learning styles.

Faculty rated the academic preparation of students in their introductory courses as, on average, below moderate or moderate. None rated students as "very well prepared" and only $6 \%$ rated them as "well prepared." There was no universal agreement on the shortcomings that students demonstrate, but responses suggested a range of problems: from a lack of general background knowledge to deficiencies in basic math and English competencies and higher-order thinking skills. One 
faculty commented, “...[There are] a lot of basic facts they don't have about the world, politics, our own nature-ones I would assume they would have-the Bill of Rights, the capitals of countries, whether countries are developing or industrial and so forth...". And another said, "They have a hard time writing sentences. They are bright kids but have a poor literacy rate...can't use words correctly, use cliches constantly. They come from a TV culture that doesn't encourage reading." A number of faculty argued that students read and think only at a surface level: "It would never dawn on them to read a paragraph twice." As a consequence, students leave too little time to complete course assignments, perform poorly, and wonder why "because I did the work." We cannot tell from the present study whether faculty's assessment of undergraduates' background and skills is accurate or whether the level of preparation has changed over time. ${ }^{2}$ It appears, however, that at the very least, there is a cultural and intellectual divide between faculty and incoming students which many faculty recognize and attempt to address in their teaching.

Further, despite faculty's obvious dismay over academic preparation for college-level work, it was not a lack of skills that faculty found most difficult in dealing with their undergraduate students, but students' lack of engagement in their own education. Again, to quote a faculty member, "[What is difficult?] Students' lack of curiosity, passion, the desire to learn versus ambition of getting through the system. The motivation, desire to excel, to do well, think well, write well. [I] don't complain about their skills...they can acquire skills. What is most challenging for me is their lack of a desire to learn." And another: "I am amazed in terms of what students are happy with. Fifty percent getting a $\mathrm{C}$ or lower grades. Often happy with that. Something is wrong about their own expectations of their performance." Lack of student motivation is not a trivial concern for educators as the positive links between motivation and learning are well-known (McKeachie et al., 1986). Unfortunately, there are no sure-fire methods of motivating students to become involved in their own learning. Grading was the

\footnotetext{
${ }^{2}$ These opinions appear to be widespread among faculty. The 1989 Carnegie report on undergraduate teaching revealed that faculty nationwide perceive incoming students as unprepared for college-level work.
} 
second greatest source of difficulty for faculty, both in terms of the assignment of grades and in terms of dealing with students who wished to contest grades.

\section{Evaluating and Improving Teaching Performance}

Formidable barriers stand in the way of improving college teaching, particularly in a research university where the values, norms, and reward structures are traditionally directed to research productivity. Certain faculty attitudes and assumptions can inhibit instructional improvement as well. For instance, the perception that content competence is not only a necessary but a sufficient condition for teaching effectiveness is not uncommon. Furthermore, teaching is often regarded as a private affair that goes on between professor and student within the confines of a classroom closed to outsiders, literally shutting out the likelihood of instructional feedback or counsel from external sources. The ambiguity that still surrounds the teaching/learning process and the mechanics of how it actually takes place can also make it difficult to communicate what good teaching is. Teaching methods can have differential results depending upon the types of students, the course content, and the overall climate of the institution (McKeachie, 1993). Teaching the same course across a number of years can be emotionally and psychologically draining, but for some, the boredom that ensues may be more tolerable than the effort required to reverse the trend. Shortages of financial support for instructional aids can also diminish enthusiasm for teaching innovations or improvements (Weimer, 1990).

Effective feedback loops between students and faculty are essential for monitoring and improving teaching performance, but they are also an important element of intrinsic satisfaction with teaching (Bess, 1977). People who are most effective at obtaining intrinsic rewards for their efforts strive to set goals where challenges run just ahead of skill levels and "where feedback can be monitored to easily modify goals," among other characteristics (Csikszentmihaly cited in Froh, Menges, \& Walker, 1993, pp. 87-88). Learning to read the cues in the classroom environment and adjust accordingly is both a useful skill 
for improving undergraduate teaching and a key to intrinsic satisfaction.

We asked faculty to think about the cues they use to monitor the effectiveness of instruction in the day-to-day classroom environment; what student behaviors are symptomatic of poor instruction; and how they address such problems in their teaching. Not surprisingly, faculty based their assessments primarily on students' attentiveness (facial expressions, note-taking, focus on teacher, absence of side conversations) and on the questions students generate and those they are able to answer. Less traditional methods of calibrating teaching effectiveness (minute papers, directly querying students about understanding, and third party observations by teaching assistants or other faculty) were rarely used.

Faculty were also asked if they sometimes felt that a class just goes "wrong." About half of faculty respondents indicated that unsuccessful teaching was characterized by students' intellectual (and social) withdrawal from the professor and the class materials (difficulties were far less likely to manifest themselves in the form of questions or even disruptive behavior). This sort of student response puts an additional onus on the faculty to continually probe and become aware of students' levels of comprehension. When a class did "go wrong," a majority (58\%) of faculty back-tracked or repeated material again. About a third of faculty also reported asking students to articulate their difficulty, and about a quarter reported changing their style of teaching (e.g., from a discussion format to more of a lecture format, or vice versa).

On a one to nine scale, with one being excellent and nine being poor, faculty reported a mean rating on student course evaluations of

\footnotetext{
3Faculty-reported student evaluations of teaching were thus between "very good" and "good." While we have no way of knowing what students' actual evaluations of these particular faculty were, data drawn from campuswide student evaluations suggest positive but somewhat more moderate student assessments of teaching. For example, on a scale of 1 "strongly agree" to 5 "strongly disagree," students' mean rating of the following items were: course well organized2.99; instructor well-prepared for class-3.26; instructor explains clearly-2.96; instructor able to make the subject interesting-2.92; and instructor stimulates my thinking -2.92 . Overall, the mean rating of the item "I learned a lot in this course" was 2.96. Though not as positive as faculty's own reports, student evaluations were, on average, favorable and indicated real strengths in faculty teaching.
} 
$2.40( \pm 1.36, \mathrm{~N}=105) .{ }^{3}$ When asked how useful student evaluations are in improving specific aspects of a course (e.g., selection of content, assignments and examinations, organization, teaching methods), about half of faculty rated student feedback as useful to very useful. In addition, student evaluations constituted the primary, if not exclusive, basis for formal departmental review of faculty teaching. Thus, while faculty may express some doubts about formal student assessments of their teaching, such assessments carry substantial weight with individual faculty and with the department and larger institution. In this context, two factors may partially explain faculty's troubled relationship with student evaluations: (1) student evaluations play an extremely large (and often exclusive) role in determining rewards for teaching performance; and (2) the summary items, which are the most reliable and central of indicators on formal student evaluations, may be difficult to translate into the more specific dimensions of curricular design and instructional technique.

About $50 \%$ of faculty indicated that they received some kind of feedback about their teaching from other faculty, and about 53\% indicated they received feedback on their teaching from their department chair. When given, evaluative feedback was infrequent and irregular or tied to annual merit raises, promotion, and tenure. Moreover, in their review, most chairpersons relied on student evaluations. About a third of the chairs also took syllabi, tests, and so forth. into account in evaluating instruction. Less than one-fifth of chairs used classroom observations (done by themselves or other faculty) in assessing faculty teaching. Faculty rated their department colleagues' mean assessment of their teaching as about $2.42( \pm 1.25, \mathrm{~N}=96)$ on a one to nine scale, with one being "excellent."

Faculty were probed about the kinds of information and resources they use to improve their teaching. Most of the improvements faculty made to their courses were based on changes in the discipline (e.g., newly published articles, texts, etc.), student evaluations, and discussion with other faculty. Less than a quarter of faculty read articles or books on teaching, less than a fifth attended workshops or seminars on teaching, and less than $10 \%$ asked fellow faculty to observe their teaching. Evidence thus suggests that while faculty are vigilant in keeping the subject matter of their courses current, they are far less 
systematic in pursuing pedagogical enhancements and innovations and, in particular, disinclined to seek peer review of their teaching.

In summary, findings reflect a more general trend in academe to structure teaching and research dimensions of the career in very different ways. In an article on how faculty change and improve their teaching, one researcher notes:

Clearly, the academic culture does not view teaching as an endeavor to be examined, discussed, and revised. It is not in the same category as scholarly writing and research. Professors have a community of scholars with whom they share their ideas about research. However, a community of teachers rarely develops; teaching remains a private affair between professor and students. It is in this isolation that individual professors must initiate and sustain change. (Stevens, 1988, p. 64)

In the research arena faculty often exchange research manuscripts and grant applications with other faculty before submission. After submission there is substantial peer review by faculty from other institutions. While there is no clear analogue for publications in the teaching domain, course syllabi seemed a reasonable proxy to inquire about. More than a quarter of the faculty had not seen any one else's syllabi in the last two years. Faculty were no more likely to share one of their syllabi with other faculty. Twenty-three percent had not given theirs to another faculty, and $28 \%$ had given a syllabus to one or two colleagues only.

\section{Teaching Satisfaction}

There is no doubt that undergraduate teaching is a challenging and time-consuming task that must compete with a multitude of other legitimate claims on faculty's limited resources of time and energy. We wondered if the press from the challenges of the task itself, the frustrations of imperfect feedback loops, or the stress imposed by competing roles and responsibilities might diminish faculty interest in and satisfaction with their role as undergraduate teachers.

Thirty-seven percent of faculty reported their professional interest in teaching and research as equal and complementary, $21 \%$ described themselves as inclining towards teaching and $40 \%$ as inclining towards research. National data offer a similar profile of the professional 
interests of faculty at other Research 1 institutions: $66 \%$ of faculty indicated their interests "lean to" or are "primarily in" research and $35 \%$ indicated their interests "lean to" or are "primarily in" teaching (Carnegie Foundation, 1989).

Findings indicated that faculty were very satisfied with what they had been able to accomplish in their teaching according to their own standards and objectives. On a scale of 1 ("not at all satisfied") to 5 ("extremely satisfied") faculty, on average, rated themselves as 3.67 ( \pm .91$)$. Faculty were asked to assess their teaching from three different perspectives: personal enjoyment, student interest, and student performance. All faculty assessments, including their own personal enjoyment, were well above moderate levels. In general, faculty derived the greatest satisfaction from seeing the intellectual progress their students make-when the "lightbulb goes on" and students begin to understand a concept or problem or become actively engaged in thinking about and discussing some aspect of the course. One faculty member expressed the satisfaction of teaching this way: "[It's] the glitter in their eyes when they 'get it'... seeing them learn." Another spoke of teaching satisfaction as a vicarious emotion: "[I'm satisfied] if students are happy with what they are doing, if they're becoming enthused about it-it's a second-hand joy." Preparing for classroom instruction energized and satisfied another: "I enjoy being 'reactivated' by having to prepare for class. Teaching is a mechanism to get me to learn-it's self-rewarding."

\section{Conclusions and Recommendations}

The findings of the current study underscore faculty commitment to undergraduate teaching and illustrate faculty's profound concern with students' intellectual development. Results belie much of the current rhetoric about faculty indifference toward teaching, indicating both substantial interest and investment of time. Results also suggest, however, how complex college teaching has become; how varied the students are in background, preparation, and motivation; how difficult it is to create an active, engaging learning environment in large lecture courses; and how faculty must juggle teaching responsibilities amidst myriad other claims on their time. Faculty are less disinterested in 
undergraduate teaching, than at times perplexed by it-perplexed by students' lack of interest in a subject matter they find compelling, by new technologies and techniques that, while ultimately helpful, take time and resources to master, and by escalating external demands to teach more and teach better, without a clear understanding of what this means or how it is to be accomplished. If faculty commitment to teaching were less steadfast, the quality of education would have declined precipitously before this point.

The study also reveals several areas where instruction can be enriched and improved:

1. Faculty may want to make earlier, more active, and more explicit efforts to socialize students into the culture of learning at the university by explicitly articulating the time demands and the study skills essential to successful academic performance.

2. As part of the effort to provide students with clear signals about expectations and performance, earlier, more frequent feedback for students is important. In many cases, faculty cannot take on the grading of another test or paper. It may be possible, however, to use technology (e.g., automatically graded and recorded computer exercises), group projects, or short in-class writing assignments (graded satisfactory/not satisfactory) as a means of offering feedback to students about their understanding of course materials and to help calibrate how effectively instruction is proceeding.

3. Most colleges and universities are rich in extracurricular resources - cultural events, lectures by distinguished faculty and artists, library collections, and increasingly powerful and accessible computer systems. One or more of these resources should be integrated into the fabric of virtually all our courses. Students' learning will be reinforced through these experiences and education will be seen as something that happens outside as well as within the classroom.

4. Faculty may want to consider using presentation media and instructional approaches that are more varied and, in particular, accommodate current students' orientation to visual information and experiential learning.

5. Faculty rely heavily on nonverbal cues to determine students' comprehension of lecture or discussion. More direct modes of assessment - for example, inquiring directly whether students comprehend, 
or requiring students to rephrase major points or to formulate questions one would want to ask about major points - may productively augment faculty's reading of students' understanding. In addition to feedback about students' mastery of materials, such strategies would help faculty model and students practice some of the study and thinking skills they should employ when completing their out-of-class reading and assignments.

6. In-class tests and exams are the primary indicators of students' performance. Our data suggest that use of a greater number and variety of measures would elicit a wider range of study strategies and offer a more complete picture of students' capabilities. Again, faculty may simply not be able to expand the base of graded activities without additional support. However, some creative approaches may help mitigate if not eliminate this problem.

7. Faculty expressed some ambivalence about student evaluations, despite their widespread use. Perhaps one problem is that in the absence of other objective indicators, student evaluations have taken on disproportionate weight in formal reviews of teaching. Student evaluations might prove more useful to faculty and reviewers when combined with other types of evaluation (peer, self) and a clearer sense of what each of these different types of information contributes to assessment of faculty's instructional performance. Student evaluations also tend to be most accurate at a global level, suggesting that quantitative data derived from standardized, machine-scorable evaluations may be productively supplemented with qualitative data from focus groups, individual student interviews, or more detailed questionnaires carried out with small samples of students.

8. Although not the focus of the current investigation, it again became clear that schools and departments must institute faculty reward systems that provide recognition for teaching as well as research.

Central to any effort to improve undergraduate instruction is the creation of an environment of respect, openness, and mutuality between faculty and student. Perhaps one of the greatest challenges both faculty and students face is to avoid the anonymity that often attends large classes and heavy loads. In working with faculty, faculty developers can help provide information about a variety of pedagogical 
techniques (multimedia, collaborative learning groups, spontaneous writing assignments) that can promote a more active and interactive teaching-learning environment. Investing time and energy developing a course places demands and responsibilities upon teacher and learner but also energizes the learning process and those involved in it; lack of change and commitment breeds passivity and disabling cynicism. Different teaching practices and philosophies enrich the learning process and offer multiple routes to educational attainment. The task ahead is to adequately support and reward good teaching in its various forms and encourage the instructional exploration which lays the groundwork for excellence in undergraduate education.

\section{References}

Angelo, T.A., \& Cross, K.P. (1993). Classroom assessment techniques: $A$ handbook for college teachers (2nd ed.). San Francisco: Jossey-Bass.

Bess, J. L. (1977). The motivation to teach. Journal of Higher Education, 48(3), 243-258.

Carnegie Foundation for the Advancement of Teaching. (1989). The condition of the professoriate: Attitudes and trends, 1989. Princeton: Princeton University Press.

Chickering, A. W., Gamson, Z. F., \& Barsi, L. M. (1987). Inventories of good practice in undergraduate education. Racine, WI: The Johnson Foundation.

Froh, R.C., Menges, R.J., \& Walker, C.J. (1993). Revitalizing faculty work through intrinsic rewards. New Directions for Higher Education, No. 81. San Francisco: Jossey-Bass.

McKeachie, W. J. (1993). Teaching tips: A guidebook for the beginning college teacher. Lexington, MA: D. C. Heath.

McKeachie, W.J., Pintrich, P.R., Lin, Y., \& Smith, D.A. (1986). Teaching and learning in the college classroom: A review of the research literature. Ann Arbor: University of Michigan.

Mingle, J. R. (1993). Faculty work and the costs/quality/access collision. AAHE Bulletin, 45(7), 3-6, 13.

National Center for Education Statistics. (1991). Faculty in higher education institutions, 1988 (NCES No. 90-365). Washington, DC: U.S. Government Printing Office.

Stevens, E. (1988). Tinkering with teaching. The Review of Higher Education, 12(1), 63-78.

Weimer, M. (1990). Improving college teaching. San Francisco: Jossey-Bass.

Wolf, B., Schmitz, T., \& Ellis, M. (1991). How students study: Views from Bloomington campus undergraduates. Bloomington: Indiana University, Office of Academic Affairs and Dean of the Faculties. 